\title{
Endothelin type A receptor inhibition normalises intrarenal hypoxia in rats used as a model of type 1 diabetes by improving oxygen delivery
}

\author{
Stephanie Franzén $^{1,2} \cdot$ Fredrik Palm ${ }^{1,2,3}$
}

Received: 29 March 2015 / Accepted: 17 June 2015 / Published online: 15 July 2015

(C) Springer-Verlag Berlin Heidelberg 2015

\begin{abstract}
Aims/hypothesis Intrarenal tissue hypoxia, secondary to increased oxygen consumption, has been suggested as a unifying mechanism for the development of diabetic nephropathy. Increased endothelin-1 signalling via the endothelin type A receptor (ETA-R) has been shown to contribute to the development of chronic kidney disease, but its role in kidney oxygen homeostasis is presently unknown.

Methods The effects of acute ETA-R inhibition ( $8 \mathrm{nmol} / \mathrm{l} \mathrm{BQ}-$ 123 for $30-40$ min directly into the left renal artery) on kidney function and oxygen metabolism were investigated in normoglycaemic control and insulinopenic male Sprague Dawley rats $(55 \mathrm{mg} / \mathrm{kg}$ streptozotocin intravenously 2 weeks before the main experiment) used as a model of type 1 diabetes.

Results Local inhibition of ETA-R in the left kidney did not affect BP in either the control or the diabetic rats. As previously reported, diabetic rats displayed increased kidney oxygen consumption resulting in tissue hypoxia in both the kidney cortex and medulla. The inhibition of ETA-Rs restored normal kidney tissue oxygen availability in the diabetic kidney by increasing renal blood flow, but
\end{abstract}

Stephanie Franzén

stephanie.franzen@liu.se

1 Experimental Renal Medicine, Division of Drug Research, Department of Medical and Health Sciences, Faculty of Health Sciences, Linköping University, 58185 Linköping, Sweden

2 Center for Medical Image Science and Visualization, Linköping University, Linköping, Sweden

3 Department of Medical Cell Biology, Division of Integrative Physiology, Uppsala University, Uppsala, Sweden did not affect oxygen consumption. Furthermore, ETA-R inhibition reduced the diabetes-induced glomerular hyperfiltration and increased the urinary sodium excretion. Kidney function in normoglycaemic control rats was largely unaffected by BQ-123 treatment, although it also increased renal blood flow and urinary sodium excretion in these animals.

Conclusions/interpretation Acutely reduced intrarenal ETA-R signalling results in significantly improved oxygen availability in the diabetic kidney secondary to elevated renal perfusion. Thus, the beneficial effects of ETA-R inhibition on kidney function in diabetes may be due to improved intrarenal oxygen homeostasis.

Keywords BQ-123 · Diabetic nephropathy · Endothelin type A receptor $\cdot$ Hypoxia $\cdot$ Kidney function $\cdot$ Rats

$\begin{array}{ll}\text { Abbreviations } \\ \mathrm{DO}_{2} & \text { Delivery of oxygen } \\ \text { ET-1 } & \text { Endothelin-1 } \\ \text { ETA-R } & \text { Endothelin A receptor } \\ \text { ETB-R } & \text { Endothelin B receptor } \\ \text { FENa } & \text { Fractional urinary excretion of } \mathrm{Na}^{+} \\ \mathrm{FF} & \text { Filtration fraction } \\ \mathrm{MAP} & \text { Mean arterial BP } \\ \mathrm{pO}_{2} & \text { Partial pressure of oxygen } \\ \mathrm{QO}_{2} & \text { Oxygen consumption } \\ \mathrm{RBF}^{+} & \text {Renal blood flow } \\ \mathrm{RVR} & \text { Renal vascular resistance } \\ \mathrm{TBARS} & \text { Thiobarbituric acid reactive substances } \\ \mathrm{TNa} & \text { Transported Na } \\ \mathrm{TNa} / \mathrm{QO}_{2} & \text { Transported } \mathrm{Na}^{+} \text {per consumed oxygen }\end{array}$




\section{Introduction}

The vasoactive peptide endothelin-1 (ET-1) is a major regulator of $\mathrm{BP}$, acting on endothelin $\mathrm{A}$ and $\mathrm{B}$ receptors (ETA-Rs and ETB-Rs) expressed in the vasculature, regulating vascular tone, as well as along the nephron, regulating $\mathrm{Na}^{+}$transport [1-3]. In the vasculature, ETA-Rs expressed on vascular smooth muscle cells induce vasoconstriction, whereas ETB-Rs expressed on the vascular endothelial cells induce nitric oxide-dependent vasodilatation [4]. However, ETB-Rs located on vascular smooth muscle cells have been reported to cause profound vasoconstriction if activated $[5,6]$.

Both receptor types are present in the kidney: in the renal vasculature for the haemodynamic regulation of local renal blood flow (RBF) and GFR, and along the nephron for $\mathrm{Na}^{+}$homeostasis $[1,2]$. In the renal vasculature, ETARs localised to the afferent arterioles induce vasoconstriction and decrease GFR, whereas ETB-Rs localised to the efferent arterioles predominantly regulate vascular tone [7]. ETA-Rs are present in the nephron, mainly in the proximal tubule and the collecting duct, but the exact functions mediated by ET-1 signalling are complex. In the straight proximal tubule, ETB-Rs mediate fluid reabsorption at low ET-1 concentrations via the activation of protein kinase C, whereas high ET-1 concentrations inhibit fluid reabsorption through the accumulation of arachidonate metabolites [8]. However, ETB-Rs mediate the production of nitric oxide and/or cyclooxygenases, with potentially potent inhibitory effects on $\mathrm{Na}^{+} / \mathrm{K}^{+}$-ATPase, epithelial sodium channel $(\mathrm{ENaC}), \mathrm{Na}-\mathrm{K}-\mathrm{Cl}$ cotransporter $(\mathrm{NKCC} 2)$ and aquaporin $2[9,10]$, resulting in an inhibition of $\mathrm{Na}^{+}$transport in most other segments of the nephron.

Sustained hyperglycaemia and the subsequent increased oxidative stress result in increased kidney oxygen consumption $\left(\mathrm{QO}_{2}\right)$ and tissue hypoxia via distinctly different mechanisms [11]. Increased mitochondrial leak respiration in combination with a reduced efficiency of tubular electrolyte transport have been proposed as the major factors contributing to the elevated $\mathrm{QO}_{2}$ in the diabetic kidney [12-14]. Furthermore, it has been proposed that increased tubular $\mathrm{Na}^{+} / \mathrm{K}^{+}$-ATPase as a result of the early diabetesinduced glomerular hyperfiltration contributes to the elevated $\mathrm{QO}_{2}$ in the diabetic kidney [15].

Given the alterations in renal haemodynamics and tubular function associated with early diabetes and the beneficial effects of ETA-R inhibition on urinary albumin excretion, glomerular damage and fibrosis in diabetes [16-18], we investigated the role of increased ETA-R signalling for mediating diabetes-induced alterations in kidney function. To do this, we applied an approach in which we acutely and selectively inhibited ETA-R signalling in the kidney without affecting the systemic circulation.

\section{Methods}

Chemicals and animals All chemicals were purchased from Sigma-Aldrich (St Louis, MO, USA) unless otherwise stated. Male Sprague Dawley rats ( $\sim 280$ g; Charles River, Sulzfeldt, Germany), used as a model of type 1 diabetes, were rendered diabetic ( $n=7$, randomly selected) with streptozotocin (55 mg/kg i.v.) and compared with age-matched normoglycaemic controls $(n=9)$. Diabetes was confirmed by measuring the blood glucose concentration (FreeStyle Lite; Abbott Laboratories, Abbott Park, IL, USA). Food and water were given ad libitum. The experimental protocol was approved by the local ethical committee and performed in accordance with the National Institutes of Health guidelines for the use and care of experimental animals.

Surgical procedure Fourteen days after the induction of diabetes, all the rats were anaesthetised with thiobutabarbital (Inactin; $120 \mathrm{mg} / \mathrm{kg}$ i.p.). Body temperature was maintained at $37.5^{\circ} \mathrm{C}$ with a servo-controlled heating pad, and tracheostomy facilitated spontaneous ventilation. Catheters were inserted into the carotid artery in order to monitor the arterial $\mathrm{BP}$, into the jugular vein for infusion of ${ }^{3} \mathrm{H}$-inulin $\left(185 \mathrm{kBq} \mathrm{h}^{-1} \mathrm{~kg}^{-1}\right.$; controls $5 \mathrm{ml} \mathrm{h}^{-1} \mathrm{~kg}^{-1}$ and diabetic animals $10 \mathrm{ml} \mathrm{h}^{-1} \mathrm{~kg}^{-1}$; American Radiolabeled Chemicals, St Louis, MO, USA) and into the bladder to allow drainage. The left kidney was immobilised in a plastic cup, and the left ureter was catheterised in order to collect urine for subsequent measurements of kidney function. A final catheter was inserted into the lumbar artery and advanced into the left renal artery in order to allow for the kidney-specific delivery of drugs without causing systemic effects. Finally, a flow probe (Transonic Systems, Ithaca, NY, USA) was placed around the left renal artery, and a recovery period of 30-40 min was started.

Dose-response relationship The dose-response relationship for the ETA-R inhibitor BQ-123 was performed as a separate series in order to determine the most appropriate dose. After a resting period, normoglycaemic rats $(n=6)$ received constant infusions of graded doses of BQ-123 (final blood concentrations $0,0.25,0.5,1,2,4,8$ and $16 \mathrm{nmol} / \mathrm{l})$ into the renal artery with 5 min measurements of mean arterial pressure (MAP) and RBF at each dose. From these results (Fig. 1), we determined that a final concentration of $8 \mathrm{nmol} / 1$ in the renal artery resulted in a maximal effect on RBF without any effect on MAP.

Measurements of kidney function After the recovery period, MAP, RBF, GFR and renal $\mathrm{Na}^{+}$handling were measured during a baseline period (30-40 $\mathrm{min}$ ) followed by an experimental period (30-40 min) during which BQ-123 was continuously infused into the renal artery [19]. Kidney tissue partial pressures 
a

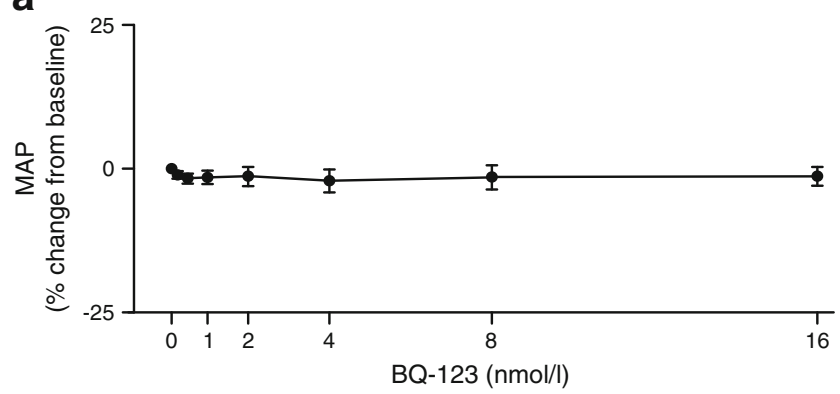

b

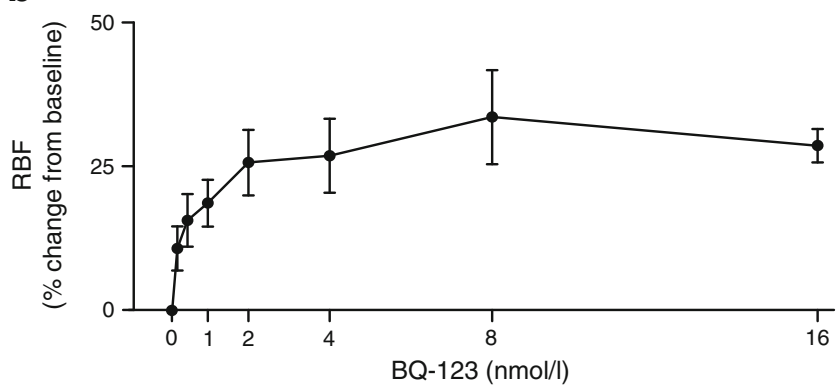

C

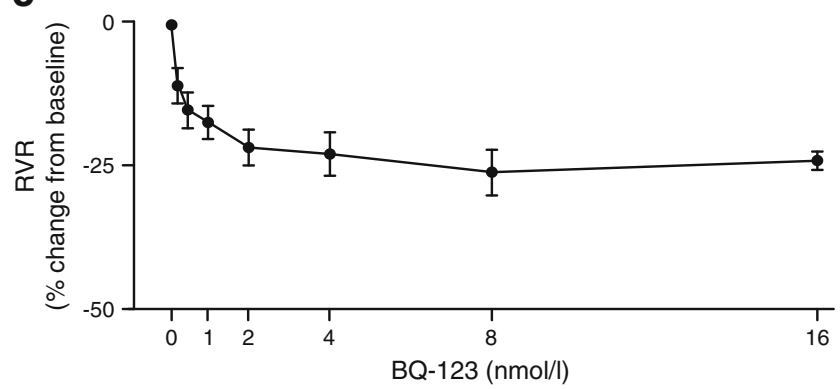

Fig. 1 Effects of increasing concentrations of the ETA-R antagonist BQ123 administered directly into the renal artery on (a) MAP, (b) RBF, and (c) calculated RVR in six normoglycaemic control rats

of oxygen $\left(\mathrm{pO}_{2}\right.$; Clark-type oxygen microelectrode, $\sim 10 \mu \mathrm{m}$ outer diameter; Unisense, Aarhus, Denmark) and total kidney $\mathrm{QO}_{2}$ (iSTAT System; Abbott Laboratories) were measured at the end of each period as described elsewhere [20, 21].

GFR was calculated from the urinary excretion rate of ${ }^{3} \mathrm{H}$-inulin using a standard liquid scintillation technique [20]. The urinary protein concentration was analysed according to the manufacturer's protocol (DC protein assay; Bio-Rad Laboratories, Sundbyberg, Sweden). $\mathrm{Na}^{+}$concentrations were analysed using flame photometry (model IL543; Instrumentation Lab, Milan, Italy), and the concentration of thiobarbituric acid reactive substances (TBARS) was measured as previously described [22].

Renal vascular resistance (RVR) was calculated as the MAP divided by the $\mathrm{RBF}$, and $\mathrm{QO}_{2}$ as the arteriovenous extraction of oxygen multiplied by the RBF. The delivery of oxygen $\left(\mathrm{DO}_{2}\right)$ was calculated as the arterial oxygen content multiplied by the $\mathrm{RBF}$. The filtration fraction (FF) was calculated as the GFR divided by $(\mathrm{RBF} \times[1-$ packed cell volume $])$. Transported $\mathrm{Na}^{+}(\mathrm{TNa})$ was calculated from (arterial $\mathrm{Na}^{+} \times \mathrm{GFR}$ )-(urinary $\mathrm{Na}^{+} \times$urine flow), and the fractional urinary excretion of $\mathrm{Na}^{+}$(FENa) from the urinary $\mathrm{Na}^{+}$concentration divided by $\left(\mathrm{GFR} \times\right.$ plasma $\left.\mathrm{Na}^{+}\right)$.

Statistical analysis All statistics were computed using GraphPad Prism 6.1 (GraphPad Software, San Diego, CA, USA). Repeated measurements $2 \times 2$ ANOVA followed by a Bonferroni's post hoc test was used to analyse control vs diabetic rats at baseline and after BQ-123 treatment. The unpaired Student's $t$ test was used to compare baseline characteristics between control and diabetic animals. All data are displayed as mean $\pm \mathrm{SEM}$, and $p<0.05$ was considered significant.

\section{Results}

The maximal effect on RBF was achieved at a concentration of $8 \mathrm{nmol} / 1$ of BQ-123 without any systemic effects (Fig. 1). This dose was therefore chosen for the subsequent studies.

All the animals administered streptozotocin developed pronounced hyperglycaemia and reduced weight gain (Table 1). The MAP, blood $\mathrm{pH}$ and haematocrit were similar in the two groups, and the administration of BQ-123 directly into the left renal artery did not affect any of these variables (Table 2).

Acute ETA-R inhibition normalised the cortical tissue $\mathrm{pO}_{2}$ in diabetic rats (Fig. 2a) but had no effect on the controls. However, ETA-R inhibition improved medullary $\mathrm{pO}_{2}$ in both groups (Fig. 2b). The diabetes-induced increase in total kidney $\mathrm{QO}_{2}$ was unaffected by ETA-R inhibition (Fig. 3a). The improved $\mathrm{pO}_{2}$ was due to an increased $\mathrm{DO}_{2}$ (Fig. 3b) resulting from pronounced vasodilatation (Fig. 4a and Table 2) and a reduced GFR (Fig. 4b). The reduction in GFR was in turn derived from a reduced FF, especially in the diabetic rats (Fig. 4c).

ETA-R inhibition increased the urinary $\mathrm{Na}^{+}$excretion as a result of a reduced $\mathrm{TNa}$ in both groups, but this was greater in the diabetic rats (Table 3). However, it is unlikely that this

Table 1 Animal characteristics

\begin{tabular}{lll}
\hline Group & $\begin{array}{l}\text { Body weight } \\
(\mathrm{g})\end{array}$ & $\begin{array}{l}\text { Blood glucose } \\
(\mathrm{mmol} / \mathrm{l})\end{array}$ \\
\hline Control $(n=9)$ & $391 \pm 7$ & $5.8 \pm 0.3$ \\
Diabetes $(n=7)$ & $339 \pm 9^{* * *}$ & $26.1 \pm 0.8^{* * *}$ \\
\hline
\end{tabular}

$* * * p<0.001$ vs control 
Table 2 MAP, RVR, arterial $\mathrm{pH}$ and haematocrit in control and diabetic rats at baseline and after blockade of intrarenal ETA-Rs using BQ-123

\begin{tabular}{llllll}
\hline Group & Acute treatment & $\begin{array}{l}\mathrm{MAP} \\
(\mathrm{mmHg})\end{array}$ & $\begin{array}{l}\mathrm{RVR} \\
\left(\mathrm{mmHg} \mathrm{m} \mathrm{min}^{-1}\right)\end{array}$ & $\begin{array}{c}\text { Arterial pH } \\
\text { Arterial haematocrit } \\
(\%)\end{array}$ \\
\hline Control $(n=9)$ & Baseline & $98 \pm 2$ & $12.0 \pm 1.0$ & $7.32 \pm 0.02$ & $41 \pm 2$ \\
& BQ-123 & $96 \pm 2$ & $9.2 \pm 0.6$ & $7.32 \pm 0.02$ & $41 \pm 1$ \\
Diabetes $(n=7)$ & Baseline & $101 \pm 3$ & $14.5 \pm 1.0$ & $7.35 \pm 0.01$ & $44 \pm 2$ \\
& BQ-123 & $100 \pm 3$ & $11.7 \pm 0.7$ & $7.35 \pm 0.02$ & $46 \pm 2$ \\
Repeated measures 2 2 ANOVA & Interaction & NS & NS & NS & NS \\
& Group & NS & NS & NS & NS \\
& Treatment & NS & $p<0.001$ & & NS \\
\hline
\end{tabular}

contributed to the improved intrarenal tissue $\mathrm{pO}_{2}$ since it concomitantly reduced the $\mathrm{TNa} / \mathrm{QO}_{2}$ (Table 3).

Acute ETA-R inhibition failed to reduce the diabetesinduced proteinuria or oxidative stress (Fig. 5).

\section{Discussion}

The main finding in the present study is that ETA-R inhibition acutely improved tissue $\mathrm{pO}_{2}$ in the diabetic kidney by increasing the $\mathrm{RBF}$ and $\mathrm{DO}_{2}$. Furthermore, ETA-R inhibition normalised the diabetes-induced hyperfiltration and induced a pronounced natriuresis. However, the total $\mathrm{QO}_{2}$ in the diabetic kidney remained unaffected, and $\mathrm{TNa} / \mathrm{QO}_{2}$ was further reduced after ETA-R inhibition. Finally, 30-40 min of acute ETA-R inhibition did not reduce either proteinuria or markers of oxidative stress.

Diabetic nephropathy is the leading cause of end-stage renal disease, affecting one-third of diabetic patients [23, 24]. The underlying mechanisms are poorly understood, and the currently available treatment strategies targeting the renin-angiotensin system have been shown to lack benefit for long-term renal function in addition to lowering BP in diabetic patients with microalbuminuria diabetes patients with a modestly reduced GFR [25]. However, the inhibition of ET-1 signalling via ETA-Rs has recently

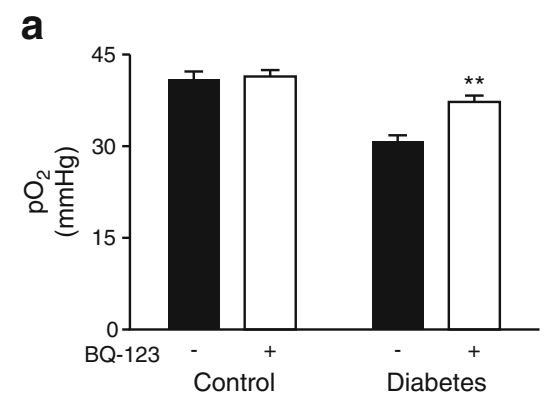

Fig. 2 Effects of ETA-R inhibition (white bars) on (a) cortical and (b) medullary kidney tissue $\mathrm{pO}_{2}$ in control $(n=9)$ and diabetic $(n=7)$ rats. Results from $2 \times 2$ ANOVA: (a) $p<0.001$ for group, $p<0.01$ for treatment emerged as a novel treatment option, and clinical trials currently validate its effectiveness [26].

ET-1 signalling via ETA-R results in pronounced vasoconstriction in most resistance vessels, as well as tubular $\mathrm{Na}^{+}$retention [27]. The involvement of ET-1, and specifically the ETA-R, is attracting growing attention, and it is now concluded that increased ETA-R signalling has an important role in the development of chronic kidney disease [27]. In terms of diabetic nephropathy, ETA-R inhibition has been reported to decrease albuminuria [16] and reduce glomerular damage [17] in vivo, and to decrease epithelial-to-mesenchymal transition-induced fibrosis in cultured renal tubular cells exposed to hyperglycaemia [18]. Circulating levels of ET-1 are elevated in diabetes [28], which may be due to either increased ET-1 production or reduced clearance. Furthermore, it was recently demonstrated that ET-1, via ETA-Rs, increases the glomerular production of reactive oxygen species and urinary protein leakage during exposure to hypoxia in mice fed a highsalt diet [29]. Thus, ET-1 signalling via ETA-Rs may play an important role in the development of diabetic nephropathy, especially considering the intrarenal hypoxia that develops soon after the onset of diabetes [30].

Intrarenal tissue hypoxia has been proposed as a unifying pathway for chronic kidney disease [31], including diabetic nephropathy [11]. Indeed, intrarenal tissue hypoxia per se

b

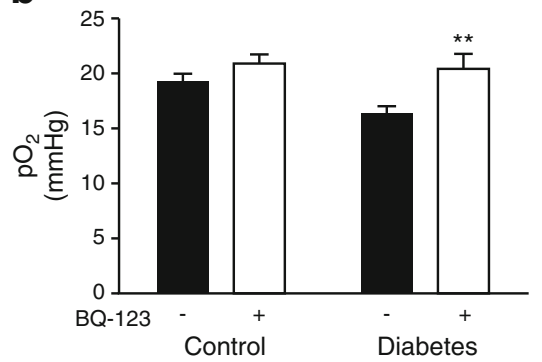

and $p<0.01$ for interaction; (b) $p<0.001$ for treatment. ${ }^{* *} p<0.01$ vs corresponding baseline 
Fig. 3 Effects of ETA-R inhibition (white bars) on (a) total kidney $\mathrm{QO}_{2}$ and (b) oxygen delivery in control $(n=9)$ and diabetic rats $(n=7)$. Results from $2 \times 2$ ANOVA: (a) $p<0.01$ for group; (b) $p<0.001$ for treatment. $* * * p<0.001$ vs corresponding baseline a

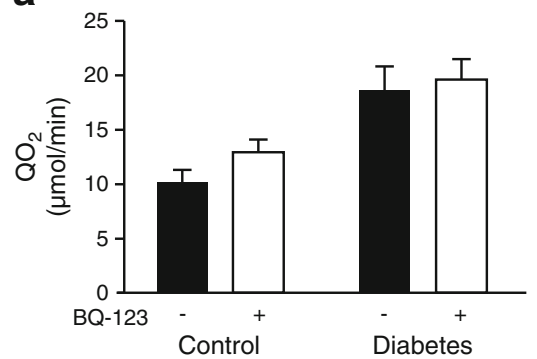

b

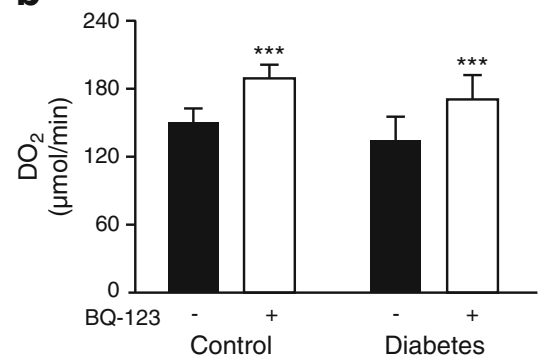

without confounding factors such as hyperglycaemia, oxidative stress or hypertension is sufficient to induce chronic kidney disease [32]. It should be noted that RBF is not under metabolic control, since it is regulated predominantly by the myogenic response and the tubuloglomerular feedback mechanism to maintain a stable GFR. As a consequence, an increased kidney

a

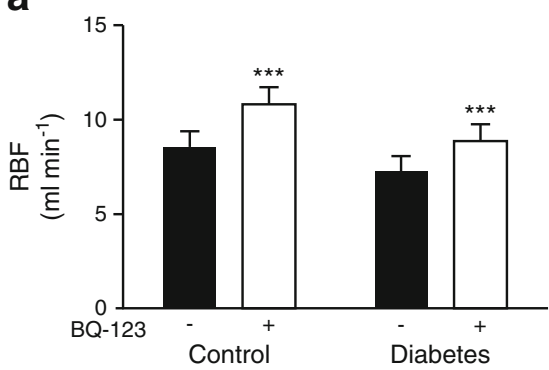

b

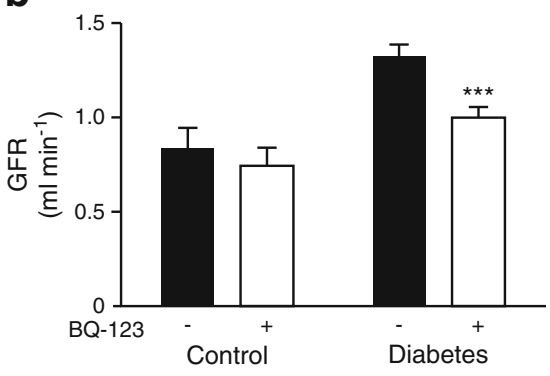

C

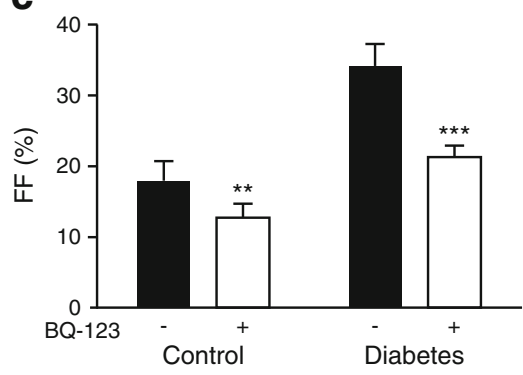

Fig. 4 Effects of ETA-R inhibition (white bars) on (a) total RBF, (b) GFR, and (c) calculated FF in control $(n=9)$ and diabetic $(n=7)$ rats. Results from $2 \times 2$ ANOVA: (a) $p<0.001$ for treatment; (b) $p<0.01$ for group, $p<0.001$ for treatment and $p<0.05$ for interaction; (c) $p<0.01$ for group, $p<0.001$ for treatment and $p<0.01$ for interaction. $* * p<0.01$ vs corresponding baseline; ${ }^{* * *} p<0.001$ vs corresponding baseline
$\mathrm{QO}_{2}$ inevitably causes intrarenal tissue hypoxia because there is a lack of a compensatory increase in $\mathrm{DO}_{2}$.

The two dominant mechanisms for the increased kidney $\mathrm{QO}_{2}$ in diabetes are increased mitochondrial leak respiration and reduced $\mathrm{TNa} / \mathrm{QO}_{2}$ [30]. Both alterations are initiated by increased oxidative stress since antioxidant treatment using Coenzyme Q10 prevented mitochondrial leak respiration [13] and the activation of hypoxia-inducible factors, resulting in a significantly upregulated antioxidant defence, normalised $\mathrm{TNa} / \mathrm{QO}_{2}$ [33]. Interventions inhibiting the key events in the pathway that leads an to increased $\mathrm{QO}_{2}$ in the diabetic kidney [30] will therefore normalise intrarenal oxygen availability and prevent the development of diabetic nephropathy [13, 33-36]. The present study demonstrates that an inhibition of ETA-R signalling in the diabetic kidney will also normalise intrarenal tissue oxygen availability, but that rather than there being a direct effect on kidney $\mathrm{QO}_{2}$, this effect is accomplished via increased $\mathrm{DO}_{2}$ due to profound vasodilatation and an increased RBF. ETA-Rs are particularly predominant in vascular smooth muscle and myocytes, which explains the profound renovascular effects of ETA-R inhibition.

The long-term implication of profound vasodilatation for diabetic kidney function has not yet been fully elucidated, but the available clinical data support beneficial effects on kidney function by reducing cell injury, inflammation and fibrosis [37]. Indeed, the renovascular response to most vasoconstrictors is enhanced in diabetes [38], and chronic ETA-R inhibition may therefore protect function in diabetic kidneys at least partly by restoring the normal vascular response to endogenous vasodilators. Furthermore, we have recently reported that immunomodulation using chronic adenosine $\mathrm{A}_{2}$ a receptor stimulation prevents diabetes-induced glomerular damage and proteinuria independently of oxidative stress and intrarenal hypoxia [39]. It is therefore possible that the long-term beneficial effect of ETA-R inhibition on glomerular integrity is due to reduced inflammatory damage to the filtration barrier, which is in addition to reduced mesangial cell contraction [40].

It is surprising that the kidney $\mathrm{QO}_{2}$ did not decrease after ETA-R inhibition in light of the reduced GFR and 
Table 3 Parameters of renal $\mathrm{Na}^{+}$handling in control and diabetic rats at baseline and after blockade of intrarenal ETA-Rs

\begin{tabular}{|c|c|c|c|c|c|}
\hline Group & Acute treatment & $\begin{array}{l}\mathrm{TNa} \\
(\mu \mathrm{mol} / \mathrm{min})\end{array}$ & $\begin{array}{l}\mathrm{UNa} \\
(\mu \mathrm{mol} / \mathrm{min})\end{array}$ & $\begin{array}{l}\text { FENa } \\
(\%)\end{array}$ & $\mathrm{TNa} / \mathrm{QO}_{2}$ \\
\hline \multirow[t]{2}{*}{ Control $(n=9)$} & Baseline & $118 \pm 15$ & $0.14 \pm 0.03$ & $0.15 \pm 0.04$ & $13.2 \pm 2.17$ \\
\hline & BQ-123 & $104 \pm 13$ & $0.36 \pm 0.13$ & $0.33 \pm 0.11$ & $8.56 \pm 1.37^{* * *}$ \\
\hline \multirow[t]{2}{*}{ Diabetes $(n=7)$} & Baseline & $186 \pm 8$ & $0.87 \pm 0.29$ & $0.50 \pm 0.16$ & $11.1 \pm 1.55$ \\
\hline & BQ-123 & $141 \pm 8^{* * *}$ & $1.78 \pm 0.34^{* * *}$ & $1.30 \pm 0.31^{* * *}$ & $7.64 \pm 0.83$ \\
\hline \multirow[t]{3}{*}{ Repeated measures $2 \times 2$ ANOVA } & Interaction & $p<0.05$ & $p<0.05$ & $p<0.01$ & NS \\
\hline & Group & $p<0.01$ & $p<0.01$ & $p<0.01$ & NS \\
\hline & Treatment & $p<0.001$ & $p<0.001$ & $p<0.001$ & $p<0.001$ \\
\hline
\end{tabular}

$* * * p<0.001$ vs corresponding baseline

$\mathrm{UNa}$, urinary $\mathrm{Na}^{+}$excretion

TNa. However, the relationship between oxygen availability and lactate production is significantly altered in diabetes [41], resulting in increased lactate levels even though there is enough oxygen present for oxidative phosphorylation [42]. It is possible that the increased $\mathrm{DO}_{2}$ after ETA-R inhibition in the diabetic kidney masked any potential beneficial effect of a reduced oxygen demand by offsetting this relationship. This would also explain the significantly reduced $\mathrm{TNa} / \mathrm{QO}_{2}$ after inhibition of ETA-R in diabetes. Furthermore, an increased RBF and concomitantly reduced FF and GFR imply a preferential effect on the efferent arteriole after ETA-R inhibition in the diabetic kidney, similar to what has been reported for C-peptide [20].

The finding of increased total and fractional urinary $\mathrm{Na}^{+}$excretion after ETA-R inhibition is in agreement with previous reports highlighting ETA-R as a major regulator of $\mathrm{TNa}$ [43]. In the present study, $\mathrm{QO}_{2}$ was unaltered whereas TNa was significantly reduced after ETA-R inhibition, resulting in a lower $\mathrm{TNa} / \mathrm{QO}_{2}$. It is well-known that the $\mathrm{TNa} / \mathrm{QO}_{2}$ ratio should be interpreted with caution when experimentally altering $\mathrm{TNa}$ (reviewed by Evans et al [44]). The lack of an acute effect of ETA-R inhibition on total kidney $\mathrm{QO}_{2}$ is possibly the result of ETA-Rs mainly being localised in the smooth muscle cells and myocytes, and not in the renal tubular cells performing the majority of work in the kidney. Although we did not observe any direct implications of a reduced $\mathrm{TNa}$ for total $\mathrm{QO}_{2}$, it is likely that the pronounced natriuretic effects after ETA-R inhibition would contribute to the reduction in BP, an effect that could magnify the beneficial effects for long-term kidney function.

Interference with any mechanism affecting systemic haemodynamic regulation has the potential to be influenced by an altered renal perfusion pressure. We therefore chose to deliver the ETA-R inhibitor directly into the left renal artery in a dose that would cause maximum renal effects without spilling over to affect the systemic BP. Using this approach enabled us to isolate the role of ETA-Rs on intrarenal haemodynamic regulation and tubular function, and to avoid confounding effects such as a reduced arterial pressure that could potentially affect sympathetic activity and induce renin release.

In conclusion, this study demonstrates that acute ETA-R inhibition increases oxygen availability in the diabetic rat kidney. The improved intrarenal oxygen availability after ETA-R inhibition was predominantly an effect of increased $\mathrm{DO}_{2}$ rather than a normalisation of the diabetes-induced increase in kidney $\mathrm{QO}_{2}$. The increased $\mathrm{RBF}$ in combination with a reduced $\mathrm{FF}$ and GFR implies that ETA-R inhibition mainly affects the efferent arterioles.
Fig. 5 Effects of ETA-R inhibition (white bars) on urinary excretion of (a) protein and (b) TBARS in control $(n=9)$ and diabetic $(n=7)$ rats. Results from $2 \times 2$ ANOVA: (a) $p<0.001$ for group; (b) $p<0.05$ for group
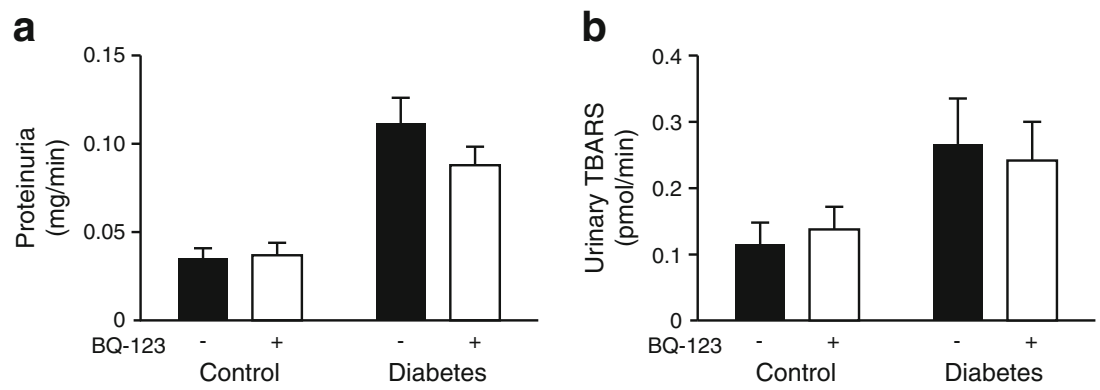
Acknowledgements M. Friederich-Persson and P. Persson, Department of Medical Cell Biology, Uppsala University, Sweden, are acknowledged for technical assistance.

Funding This project was funded by the Swedish Research Council, the Swedish Diabetes Foundation and the Family Ernfors Fund.

Duality of interest The authors declare that there is no duality of interest associated with this manuscript.

Contribution statement SF and FP were responsible for the conception and design of the study, for the analysis and interpretation of the data, and for revising the article critically for intellectual content. SF drafted the article. Both authors gave final approval of the version to be published. SF is the guarantor of this work.

\section{References}

1. Hocher B, Rohmeiss P, Diekmann F et al (1995) Distribution of endothelin receptor subtypes in the rat kidney. Renal and haemodynamic effects of the mixed $(\mathrm{A} / \mathrm{B})$ endothelin receptor antagonist bosentan. Eur J Clin Chem Clin Biochem 33:463-472

2. Vignon-Zellweger N, Heiden S, Miyauchi T, Emoto N (2012) Endothelin and endothelin receptors in the renal and cardiovascular systems. Life Sci 91:490-500

3. Kaasjager KA, Shaw S, Koomans HA, Rabelink TJ (1997) Role of endothelin receptor subtypes in the systemic and renal responses to endothelin-1 in humans. J Am Soc Nephrol 8:32-39

4. Clozel M, Gray GA, Breu V, Loffler BM, Osterwalder R (1992) The endothelin ETB receptor mediates both vasodilation and vasoconstriction in vivo. Biochem Biophys Res Commun 186:867-873

5. Seo B, Oemar BS, Siebenmann R, von Segesser L, Luscher TF (1994) Both ETA and ETB receptors mediate contraction to endothelin-1 in human blood vessels. Circulation 89:1203-1208

6. Haynes WG, Strachan FE, Webb DJ (1995) Endothelin ETA and ETB receptors cause vasoconstriction of human resistance and capacitance vessels in vivo. Circulation 92:357-363

7. Gulbins E, Hoffend J, Zou AP et al (1993) Endothelin and endothelium-derived relaxing factor control of basal renovascular tone in hydronephrotic rat kidneys. J Physiol 469:571-582

8. Garcia NH, Garvin JL (1994) Endothelin's biphasic effect on fluid absorption in the proximal straight tubule and its inhibitory cascade. J Clin Invest 93:2572-2577

9. Pollock JS, Pollock DM (2008) Endothelin and NOS1/nitric oxide signaling and regulation of sodium homeostasis. Curr Opin Nephrol Hypertens 17:70-75

10. Kohan DE, Rossi NF, Inscho EW, Pollock DM (2011) Regulation of blood pressure and salt homeostasis by endothelin. Physiol Rev 91:1-77

11. Palm F (2006) Intrarenal oxygen in diabetes and a possible link to diabetic nephropathy. Clin Exp Pharmacol Physiol 33:997-1001

12. Friederich M, Olerud J, Fasching A, Liss P, Hansell P, Palm F (2008) Uncoupling protein-2 in diabetic kidneys: increased protein expression correlates to increased non-transport related oxygen consumption. Adv Exp Med Biol 614:37-43

13. Persson MF, Franzen S, Catrina SB et al (2012) Coenzyme Q10 prevents GDP-sensitive mitochondrial uncoupling, glomerular hyperfiltration and proteinuria in kidneys from $\mathrm{db} / \mathrm{db}$ mice as a model of type 2 diabetes. Diabetologia 55:1535-1543

14. Friederich M, Fasching A, Hansell P, Nordquist L, Palm F (2008) Diabetes-induced up-regulation of uncoupling protein-2 results in increased mitochondrial uncoupling in kidney proximal tubular cells. Biochim Biophys Acta 1777:935-940
15. Korner A, Eklof AC, Celsi G, Aperia A (1994) Increased renal metabolism in diabetes. Mechanism and functional implications. Diabetes 43:629-633

16. Sasser JM, Sullivan JC, Hobbs JL et al (2007) Endothelin A receptor blockade reduces diabetic renal injury via an anti-inflammatory mechanism. J Am Soc Nephrol 18:143-154

17. Hocher B, Schwarz A, Reinbacher D et al (2001) Effects of endothelin receptor antagonists on the progression of diabetic nephropathy. Nephron 87:161-169

18. Tang L, Li H, Gou R et al (2014) Endothelin-1 mediated high glucose-induced epithelial-mesenchymal transition in renal tubular cells. Diabetes Res Clin Pract 104:176-182

19. Patinha D, Fasching A, Pinho D, Albino-Teixeira A, Morato M, Palm F (2013) Angiotensin II contributes to glomerular hyperfiltration in diabetic rats independently of adenosine type I receptors. Am J Physiol Renal Physiol 304:F614-F622

20. Nordquist L, Brown R, Fasching A, Persson P, Palm F (2009) Proinsulin C-peptide reduces diabetes-induced glomerular hyperfiltration via efferent arteriole dilation and inhibition of tubular sodium reabsorption. Am J Physiol Renal Physiol 297:F1265F1272

21. Persson P, Hansell P, Palm F (2012) NADPH oxidase inhibition reduces tubular sodium transport and improves kidney oxygenation in diabetes. Am J Physiol Regul Integr Comp Physiol 302:R1443R1449

22. Franzen S, Friederich-Persson M, Fasching A, Hansell P, Nangaku M, Palm F (2014) Differences in susceptibility to develop parameters of diabetic nephropathy in four mouse strains with type 1 diabetes. Am J Physiol Renal Physiol 306:F1171-F1178

23. Molitch ME, DeFronzo RA, Franz MJ et al (2004) Nephropathy in diabetes. Diabetes Care 27(Suppl 1):S79-S83

24. Hovind P, Tarnow L, Rossing P et al (2004) Predictors for the development of microalbuminuria and macroalbuminuria in patients with type 1 diabetes: inception cohort study. BMJ 328:1105

25. Yamout H, Lazich I, Bakris GL (2014) Blood pressure, hypertension, RAAS blockade, and drug therapy in diabetic kidney disease. Adv Chronic Kidney Dis 21:281-286

26. Kohan DE, Barton M (2014) Endothelin and endothelin antagonists in chronic kidney disease. Kidney Int 86:896-904

27. Pollock DM (2014) 2013 Dahl Lecture: American Heart Association council for high blood pressure research clarifying the physiology of endothelin. Hypertension 63:e110-e117

28. Takahashi K, Ghatei MA, Lam HC, O'Halloran DJ, Bloom SR (1990) Elevated plasma endothelin in patients with diabetes mellitus. Diabetologia 33:306-310

29. Heimlich JB, Speed JS, Bloom CJ, O'Connor PM, Pollock JS, Pollock DM (2015) ET-1 increases reactive oxygen species following hypoxia and high-salt diet in the mouse glomerulus. Acta Physiol (Oxf) 213:722-730

30. Hansell P, Welch WJ, Blantz RC, Palm F (2013) Determinants of kidney oxygen consumption and their relationship to tissue oxygen tension in diabetes and hypertension. Clin Exp Pharmacol Physiol 40:123-137

31. Nangaku M (2006) Chronic hypoxia and tubulointerstitial injury: a final common pathway to end-stage renal failure. J Am Soc Nephrol 17:17-25

32. Friederich-Persson M, Thorn E, Hansell P, Nangaku M, Levin M, Palm F (2013) Kidney hypoxia, attributable to increased oxygen consumption, induces nephropathy independently of hyperglycemia and oxidative stress. Hypertension 62:914-919

33. Nordquist L, Friederich-Persson M, Fasching A et al (2015) Activation of hypoxia-inducible factors prevents diabetic nephropathy. J Am Soc Nephrol 26:328-338

34. Palm F, Cederberg J, Hansell P, Liss P, Carlsson PO (2003) Reactive oxygen species cause diabetes-induced decrease in renal oxygen tension. Diabetologia 46:1153-1160 
35. Palm F, Hansell P, Ronquist G, Waldenstrom A, Liss P, Carlsson PO (2004) Polyol-pathway-dependent disturbances in renal medullary metabolism in experimental insulin-deficient diabetes mellitus in rats. Diabetologia 47:1223-1231

36. Edlund J, Fasching A, Liss P, Hansell P, Palm F (2010) The roles of $\mathrm{NADPH}$-oxidase and nNOS for the increased oxidative stress and the oxygen consumption in the diabetic kidney. Diabetes Metab Res Rev 26:349-356

37. Gagliardini E, Zoja C, Benigni A (2015) ET and diabetic nephropathy: preclinical and clinical studies. Semin Nephrol 35:188-196

38. Schnackenberg CG (2002) Physiological and pathophysiological roles of oxygen radicals in the renal microvasculature. Am J Physiol Regul Integr Comp Physiol 282:R335-R342

39. Persson $P$, Friederich-Persson $M$, Fasching A, Hansell $P$, Inagi R, Palm F (2015) Adenosine A2a receptor stimulation prevents proteinuria in diabetic rats by promoting an anti-inflammatory phenotype without affecting oxidative stress. Acta Physiol (Oxf) 214:311-318
40. Badr KF, Murray JJ, Breyer MD, Takahashi K, Inagami T, Harris RC (1989) Mesangial cell, glomerular and renal vascular responses to endothelin in the rat kidney. Elucidation of signal transduction pathways. J Clin Invest 83:336-342

41. Laustsen C, Lycke S, Palm F et al (2014) High altitude may alter oxygen availability and renal metabolism in diabetics as measured by hyperpolarized [1-(13)C]pyruvate magnetic resonance imaging. Kidney Int 86:67-74

42. Williamson JR, Chang K, Frangos M et al (1993) Hyperglycemic pseudohypoxia and diabetic complications. Diabetes 42:801-813

43. Kohan DE (2013) Role of collecting duct endothelin in control of renal function and blood pressure. Am J Physiol Regul Integr Comp Physiol 305:R659-R668

44. Evans RG, Harrop GK, Ngo JP, Ow CP, O’Connor PM (2014) Basal renal $\mathrm{O}_{2}$ consumption and the efficiency of $\mathrm{O}_{2}$ utilization for $\mathrm{Na}+$ reabsorption. Am J Physiol Renal Physiol 306:F551-F560 